\title{
Cultural competence: a key component for training global citizens
}

\author{
McHugh-Cole, Amy B.; Russell-Mundine, Gabrielle S. and Simons, Rachael F.
}

National Centre for Cultural Competence, The University of Sydney, Australia

\begin{abstract}
As globalization continues to make cross-cultural interactions more of a reality, the need to develop the cultural competence of students and staff is imperative. The University of Sydney has included cultural competence in its 2016-20 strategic plan, necessitating the embedding of cultural competence across all functions of the University. The National Centre for Cultural Competence (NCCC) at The University of Sydney was created to lead the thinking on cultural competence, which includes creating teaching and learning resources to guide University students and staff on their cultural competence journey. In this paper, we discuss a cultural competence seminar developed and delivered by the NCCC to students participating in a broader program designed to educate and prepare them to be global citizens. We will examine the efficacy of our approach to cultural competence training with this particular cohort of students.
\end{abstract}

Keywords cultural competence; global citizenship; globalization; higher education; Indigenous; Australia. 


\section{Introduction}

The world has altered dramatically over the past few decades as a result of globalization (Zolo, 2007). Technology, modern communication, and enhanced infrastructure has made communication and travel easier, cheaper, and more reliable. As well, global migration movements mean that interactions among people from disparate backgrounds are more common. Whether through travel or in the workplace, the potential for daily interactions with diverse groups of people creates the need for culturally competent global citizens: those who can work respectfully and effectively in a myriad of contexts, have an awareness (of themselves and others), and who are committed to making things more equitable for all in their areas of influence (Sherman, 2017).

The concept of the 'global citizen' is particularly pertinent in the higher education landscape. At The University of Sydney (the University), almost half of the employees (academic and professional staff) originate from more than 100 different countries. As well, $38 \%$ of the University's student body is made up of students from more than 170 countries (Mery Joseph, HR Research, Analysis \& Reporting, personal communication, January 29, 2018). Working and/or interacting with culturally and linguistically diverse people is to be expected within this University community, which prioritizes developing cultural competence in its staff and graduates (The University of Sydney, 2016, pg. 58).

This paper reports on one cultural competence development seminar delivered as part of a larger University program: the Global Citizenship Award (GCA) program. The GCA program "provides distinctive international and leadership opportunities to prepare students as global citizens. GCA participants attend speaker events and practical skills development seminars around the key themes of global citizenship, leadership in an international context, and community and diversity,” (The University of Sydney, 2018). The program is open to both domestic and international students from all disciplines.

\subsection{Cultural competence and global citizenship}

Funded by a federal grant, the University of Sydney's National Centre for Cultural Competence (NCCC) was created in 2014 to lead the thinking and praxis of cultural competence within and beyond the University. The NCCC views cultural competence as the ability to participate ethically and effectively in personal and professional intercultural settings. "It requires being aware of one's own cultural values and world view [sic] and their implications for making respectful, reflective and reasoned choices, including the capacity to imagine and collaborate across cultural boundaries. Cultural competence is, ultimately, about valuing diversity for the richness and creativity it brings to society," (The University of Sydney, n.d.). The NCCC specifically locates its understanding of cultural competence in Aboriginal and Torres Strait Islander peoples' contexts. Universities have 
traditionally not encouraged or enabled Aboriginal and Torres Strait Islander peoples' participation in higher education whether that was as students, researchers, teachers or professional staff. The NCCC aims to highlight Aboriginal and Torres Strait Islander peoples' different ways of knowing, being, and doing, and draw attention to the social justice aspects of cultural competence and global citizenship.

There is consensus that 'global citizenship' refers to those who "recognize the interconnectedness of life, respect cultural diversity and human rights, advocate global social justice, empathize with suffering people around the world, see the world as others see it and feel a sense of moral responsibility for planet Earth," (Sherman, 2017). It is for this reason that the NCCC partnered with the Office of Global Engagement to create mandatory cultural competence seminars as part of the Global Citizenship Award program.

\subsection{The program}

The University has committed to providing students with multiple opportunities to build their capabilities as global citizens, thereby supporting the strategic goal of graduating "culturally competent" students. The cultural competence component of the GCA program, created and facilitated by the NCCC, is positioned within the required development seminar section of the program. The cultural competence seminar consists of two components; a two-hour session on critical self-reflection which gets students exploring their values, attitudes, and personal histories (Sisneros, 2008), and a three-hour session which includes a lecture on Aboriginal and Torres Strait Islander Australians' history and context for cultural competence, followed by the setting of a safe space, and continuing with practical work on improving cultural competence capabilities (i.e. behaviors, attitudes, skills, and knowledge). Including Aboriginal and Torres Strait Islander peoples' histories and perspectives is important not only because the NCCC locates its understanding of cultural competence within these contexts, but also because participants in the GCA program generally have limited knowledge of Aboriginal and Torres Strait Islander history in Australia. The NCCC considers that this is an important aspect of our seminar because all of our work takes place on colonised and unceded land. For 150 years, the University has inhabited the land of the Gadigal Peoples of the Eora Nation, and has taught generations of students from a Western knowledge perspective, while diminishing the validity and agency of Aboriginal and Torres Strait Islander peoples' and their knowledge systems.

Through understanding cultural competence as a "philosophy, a paradigm and praxis" (NCCC, 2015), the NCCC works to create transformative opportunities to engage Indigenous knowledge practices and research methods to grow pedagogical models for teaching and learning (Sherwood \& Russell-Mundine, 2017, pg. 143). Central to this pedagogical model is the focus on facilitating opportunities for staff and students to understand more about themselves as cultural people. The tendency for those of dominant 
groups to avoid, or indeed resist, racialized dialogue (DiAngelo, 2011) means that for many people, exploring their cultural identities can be both new and daunting. Developing resources that engage and provoke participants to think deeply about themselves (i.e. why they think and act the way they do) in a safe environment is a significant challenge. Therefore, it was imperative that a review of the NCCC's aspect of the GCA program be undertaken, to ensure our pedagogical model was effective.

The facilitators of the seminars aim to deliver the content in a way that is accessible to a large group of undergraduate university students whose knowledge of cultural competence prior to the seminar is unknown. Before attending the development seminars, students are asked to complete two online modules created by the NCCC called "Journey of selfdiscovery," and "What do you mean by "cultural competence"?" This is done to ensure students come to the program with a base level of knowledge. Students are then guided through activities that assist them to understand how their own worldview and socialization affects the ways in which they think, act, and interact.

\section{Method}

In order to evaluate the effectiveness of our seminars, participants were invited to fill out an online survey via Survey Monkey after attending one of the cultural competence seminars. Participants were contacted by the head of the GCA program with the link to the survey, indicating they were welcome to provide feedback on the seminar, but that participation was voluntary. Ethics approval for this research was sought and granted by the University's ethics committee.

Data was collected over a period of 6 months in 2017 with a $38 \%$ response rate (82 respondents in total). A mixed-methods approach was used, asking participants to answer multiple choice, matrix/scale rating, and open-ended questions. Descriptive statistics and thematic analysis were used to analyse the data and to help answer our research question:

R1: Were our development seminars effective in educating participants about the various aspects of cultural competence?

\subsection{Data}

Participants were first asked whether the content of the topic covered in the seminar was presented in a logical manner. Of the 82 respondents, $100 \%$ answered in the affirmative.

The second section of the survey asked participants to rate the effectiveness of various aspects and outcomes of the seminar on a four point Likert type scale (as seen in Table 1). 
Table 1. Seminar Effectiveness

\begin{tabular}{lllll}
\hline \multicolumn{7}{c}{} & $\begin{array}{l}\text { Highly } \\
\text { effective }\end{array}$ & Effective & Not effective & Useless \\
\hline $\begin{array}{l}\text { How effective was this } \\
\text { workshop in providing initial } \\
\text { information about cultural }\end{array}$ & $47 \%$ & $52 \%$ & $1 \%$ & 0 \\
\hline $\begin{array}{l}\text { How effective was this } \\
\text { workshop in helping you }\end{array}$ & & & \\
understand how to develop \\
your cultural competence
\end{tabular}

Source: National Centre for Cultural Competence (2018).

Three additional quantitative questions were asked, but due to technical issues, the reliability of the data could not be confirmed with that particular set of questions. Therefore, that data was excluded from the analysis.

Finally, a thematic analysis was conducted for the qualitative components of the evaluation survey. Two open-ended questions were asked: "Which feature, activity or interaction in the workshop was the most helpful to you?"; and, "What feature, activity or interaction in the workshop do you think needs to be improved?" The final component of the survey was an open-ended statement: "Feel free to provide any additional feedback in the space below." Several key themes emerged under each open-ended question (see Tables $2 \& 3$ ).

Table 2. Themes regarding feature/activity/interaction that was helpful

\begin{tabular}{lc}
\hline Theme & Percentage \\
\hline Interaction with peers & $38 \%$ \\
\hline Resources (videos) & $25 \%$ \\
\hline Self-reflection & $13 \%$ \\
\hline Indigenous content & $12 \%$ \\
\hline
\end{tabular}

Source:Natioal Centre for Cultural Competence (2018). 
Table 3. Themes regarding feature/activity/interaction that needs improvement

\begin{tabular}{lc}
\hline Theme & Percentage \\
\hline $\begin{array}{l}\text { Presentation (delivery, } \\
\text { facilitation, content) }\end{array}$ & $18 \%$ \\
\hline $\begin{array}{l}\text { More interaction with other } \\
\text { participants (peers) }\end{array}$ & $17 \%$ \\
\hline $\begin{array}{l}\text { Seminar length (too long) } \\
\text { Seminar length (too short) }\end{array}$ & $10 \%$ \\
\hline $\begin{array}{l}\text { Want more practical } \\
\text { applications of cultural } \\
\text { competence }\end{array}$ & $6 \%$ \\
\hline $\begin{array}{l}\text { Said 'nothing needs } \\
\text { improvement' specifically }\end{array}$ & $6 \%$ \\
\hline
\end{tabular}

Source: National Centre for Cultural Competence (2018).

The most notable theme that emerged from the feedback was the respondents' positive response to activities that required peer interaction. Respondents highlighted that the socialization activity - where students asked their peers set questions on the topics: family places place, class, religion, race, and gender - was one of the most helpful components of the seminar. This exercise provided students with the opportunity to engage with diverse cultural worldviews. As one student articulated:

"I was inspired by the fact the workshop was oriented in a way to draw our attention to the social norms of different culture, this was incredibly helpful."

Another student identified that the most helpful aspects of the seminar were:

"the [sic] activities where we got to network and meet new people but also delve into our similarities and differences in world view [sic]."

The positive response to the interactive group components of the workshop was reinforced overall in the respondents' suggestions on areas for improvement:

"I think less presentation and engaging group activity would be better.";

"I would have liked a bit more interactive group work with other people attending the seminar."

These comments reveal students' shared desire for greater engagement with fellow members of the student body. 
Self-reflection emerged as another theme, most notably, through a number of responses to the question regarding which features were most helpful:

"Looking at ones [sic] own culture in order to better understand cultural differences.";

"thinking [sic] about my own identity as $i$ [sic] always think about others but have never really thought about mine.";

"The questions in the workbook really made me reflect on my own understanding of cultural competence and think critically about my own personal world view [sic]."

These responses support the effectiveness of the seminar as, from the Centre's perspective, self-reflection is a critical part of the cultural competence journey.

Eighteen percent $(18 \%)$ of participants felt different aspects of the presentation could be improved:

"The lecture part was too rushed so it lacked depth and impact.";

"First half of the workshop didn't seem to have as much purpose as the second.";

"There was a lot of the information on the slides that was hard to unpack in a short amount of time.";

As well, ten percent (10\%) of respondents felt the seminar was too long: "The first part where we had the lecture is a little long and it makes people get bored." While six percent $(6 \%)$ thought it was too short: "Timing could be improved (i.e. more time for the second half)."

\section{Discussion and conclusion}

This data reveals that our pedagogical model for delivering cultural competence to respondents is generally effective. The positive feedback on peer interaction suggests that our inclusion of this type of pedagogy is effective. It is vital for students participating in a global citizenship program to interact with those who have diverse worldviews, and our seminar provides a safe space for those interactions to occur. While the data does show some contradictions (i.e. a percentage preferred a shorter seminar, while others wanted a longer seminar), we recognize the nature of this work holds many tensions. As the journey towards cultural competence is long, we recognize that students will be at different points along their journey, making this program too cursory for some ("It could have gone more in depth but I think this is maybe because I have had more experience talking about 
these things being $4^{\text {th }}$ year and having friends interested in these issues"), or too intense for others ("Shorten the time to an hour. We don't need 3 hours to acquire such knowledge.")

Overall it is evident that students are interested in working together with their peers to work towards becoming more culturally competent global citizens. This feedback has encouraged us to make clearer our purpose for including Aboriginal and Torres Strait Islander histories and contexts, and for choosing the activities that we do.

Were our development seminars effective in educating participants about the various aspects of cultural competence? We believe the data points to 'yes'. The lifelong journey towards cultural competence will never be complete (National Centre for Cultural Competence, 2016). However, the data indicates that for this cohort of students, our seminars, which develop various aspects of cultural competence (i.e. exposure to various worldviews and practicing critical self-reflection), was effective.

\section{References}

DiAngelo, R. (2011). White Fragility. International Journal of Critical Pedagogy, 3(3), 5470.

National Centre for Cultural Competence. (2016). What is cultural competence? Retrieved 24 January 2018 from http://sydney.edu.au/nccc/about/culturalcompetence.shtml

NCCC. (2015). Rolling out cultural competence. In University of Sydney (Ed.), Internal policy document.

Sherman, P. (September 30, 2017). Why the world needs more global citizens. The Conversation. Retrieved 1 February 2018, from https://theconversation.com/why- theworld-needs-more-global-citizens- 84680

Sherwood, J., \& Russell-Mundine, G. (2017). How We Do Business: Setting the Agenda for Cultural Competence at the University of Sydney. In J. Frawley, S. Larkin, \& J. A. Smith (Eds.), Indigenous Pathways, Transitions and Participation in Higher Education: From Policy to Practice. Singapore: Springer.

Sisneros, J. (2008). Self-Awareness, Critical Reflectivity, and Identity. In J. Sisneros (Ed.), Critical Multicultural Social Work (pp. 20-37). Chicago: Lyceum Books.

The University of Sydney. (n.d.). National Centre for Cultural Competence. Retrieved 24 January 2018 from http://sydney.edu.au/nccc/

The University of Sydney. (2016). The University of Sydney 2016-20 Strategic Plan. Retrieved 24 January 2018 from https://sydney.edu.au/strategy

The University of Sydney. (2018). Global citizenship award. Retrieved 24 January 2018 from https://sydney.edu.au/students/global-citizenship-award.html

Zolo, D. (2007). Globalisation: An overview. Colchester, UK: ECPR Press. 